\title{
A STUDY ON THE METHOD OF ESTIMATING ENVIRONMENTAL LOAD ON EARTHWORK
}

\author{
Min Ho Kang, and Hyung Keun Park* \\ Department of Civil Engineering, Chung-buk University, Cheongju, Korea \\ *Corresponding author (parkhk@chungbuk.ac.kr)
}

\begin{abstract}
Great efforts have been made worldwide to reduce the Green House Gas (GHG) emission following the "Kyoto Protocol" declared during the United Nations Framework Convention on Climate Change in 1997. Many industries have restructured to meet the standard set by the Protocol. In construction industry, however, no clear guidance has been established for the purpose of reducing the GHG emission.

In Korea, the effort to reduce the environmental pollution by construction industry has been behind compared with the rate of economic growth. In addition, although construction industry is one of the most energy-consuming sectors, no significant effort has been made to conserve the energy during construction activities. For more effective energy saving in construction industry, with the current trend of mega-project, it is essential to collect data about energy consumption, quantity of environmental emissions and environmental costs. However, due to the difficulties of collecting such data, most studies on sustainable construction have been concentrated on the use of equipment, maintenance and repair works during construction.

In this study we used the data base (DB) suggested by the Ministry of Knowledge Economy and Ministry of Environment of Korea in calculating the pollutant emission during earthwork, and suggests a method in selecting the most environmentally friendly equipment combination for construction.
\end{abstract}

Keywords: LCA, Earthwork, Environmental Load, Green House Gas

\section{INTRODUCTION}

In Korea, compared with the economic advancement of the country, a large environmental pollution has been produced as the portion of energy consuming industries increases. With this in background, inefficient energy conservation of the construction sector, which is one of the most energy consuming industries, has been an issue. With the increasing number of projects and its scale, the dependency to large heavy equipment has been increased, resulting in increased energy consumption followed by increased emission of environmental pollution. To calculate an LCA for a construction project, it is typical to assume all equipment be the same. However, in reality, based on the site conditions and available equipment, various types of equipment are mobilized for construction. Therefore, in order to make the energy conservation effort be more effective in construction industry, it is necessary to establish the $\mathrm{DB}$ with respect to energy consumption during construction, quantity of environmental pollution and cost for environmental remediation, as well as to develop a plan for efficient utilization of the DB.

\section{SCOPE AND METHOD OF RESEARCH}

In general, construction project includes earthwork which takes up about 25 50\% of the total budget. Since earthwork requires utilization of heavy equipment, a large amount of environmental pollution is generated during earthwork activities. Up until now, most studies about LCA calculation has been performed based on the environmental load for each construction material except a few studies that calculate the environmental load at each construction stage. However, in Korea, environmental load has been obtained en masse from either total diesel consumption or quantity of the work data for construction equipment provided by Korea Construction Promotion Association. Since there has been no particular research about earthwork, in order to demonstrate the way to select an optimized equipment combination, the environmental load for bulldozer and excavator was calculated from the 
Standard of Estimate suggested by Korea Institute of Construction Technology (KICT). In this study, compared with the existing method, a more accurate calculation method for environmental load during earthwork was suggested.

\section{EARTHWORK, LCA ANALYSIS AND THE OUTCOME}

In earthwork, as the scale of project gets bigger, large mechanical equipment are mobilized for the project, which directly relates to increasing energy consumption. The energy consumption by earthwork equipment is limited to the fuel consumption of the equipment itself which can vary depending on many factors including combination of the equipment, ageing, and the operator's skill. In this study, due to the difficulties of including many variables, the research was performed using only two equipment, bulldozer and excavator. In addition, the Standard of Estimate was applied in the calculation to simplify the research. In this study, work load for the equipment was calculated using the Standard of Estimate, then the environmental load from the work load in accordance with the equipment size. The calculations indicate the best and the worst equipment combinations can be achieved with respect to the environmental load as shown in Table 1.

Table 1 Best and Worst Equipment Combination

\begin{tabular}{c|c|c}
\hline & $\begin{array}{c}\text { Bulldozer 13ton+ } \\
\text { Excavator } 2 \mathrm{~m}^{3}\end{array}$ & $\begin{array}{c}\text { Bulldozer 15ton+ } \\
\text { Excavator 0.7 } \mathrm{m}^{3}\end{array}$ \\
\hline $\begin{array}{c}\text { Aboitic Resources } \\
\text { Depletion }\end{array}$ & $5.47 \mathrm{E}+02$ & $2.79 \mathrm{E}+02$ \\
\hline Global Warming & $1.76 \mathrm{E}+06$ & $8.94 \mathrm{E}+05$ \\
\hline $\begin{array}{c}\text { Ozone Layer } \\
\text { Depletion }\end{array}$ & $4.38 \mathrm{E}-05$ & $2.23 \mathrm{E}-05$ \\
\hline $\begin{array}{c}\text { Photochemical } \\
\text { Oxidant Creation }\end{array}$ & $3.66 \mathrm{E}-01$ & $1.86 \mathrm{E}-01$ \\
\hline Air Acidification & $1.22 \mathrm{E}+01$ & $6.22 \mathrm{E}+00$ \\
\hline Eutrophication & $7.07 \mathrm{E}-03$ & $3.18 \mathrm{E}-03$ \\
\hline Eco-toxicity & $3.80 \mathrm{E}+00$ & $1.94 \mathrm{E}+00$ \\
\hline Human Toxicity & $6.54 \mathrm{E}-01$ & $3.33 \mathrm{E}-01$ \\
\hline
\end{tabular}

The LCA evaluation, under the assumed conditions for the study, indicates that there are twice as much environmental load differences between the best and worst equipment combination for earthwork. It suggests that environmental load can be reduced by selecting proper equipment combination. In order to establish an environmentally friendly construction trend, such environmental factors should not be ignored. Therefore, in order to execute construction project in a most optimal condition, LCA analysis should be performed along with the feasibility as well as the economic analyses.

\section{CONCLUSIONS}

Conclusions of this study are summarized as follow:

- Depending on the selected equipment combination, environmental load can vary even for a same earthwork. In order to minimize the environmental load, it is necessary to perform the LCA analysis to select a proper equipment combination.

In this study, a highest environmental load was calculated when a 13-ton bulldozer and a 2- $\mathrm{m}^{3}$ excavator are utilized, and the lowest with a 15-ton bulldozer and $0.7-\mathrm{m}^{3}$ excavator.

- It was very difficult to use the current Standard of Estimate by KICT due to missing equipment on the list or a lack of standard guideline for environmental emission (like the Standard Labor Counting in Japan). Therefore, it is required to upgrade the Standard of Estimate or provided with supplemental data to make it feasible to use for the LCA analysis.

\section{REFERENCES}

1. Jin-Suk Moon, LCA Analysis and Case Study of Environment Factors for Highway Construction Project, 2009

2. Korea Institute of Construction Technology, Standard Estimating, 2009

3. Won-Ju Kim, Environmental Assessment for the Recycling of Waste Concrete using Life Cycle Assessment Method, 2002 